\title{
P057. Prophylaxis with low-dose methadone in patients affected by daily refractory headache and medication-overuse headache: a prospective cohort study (METACEF study)
}

\author{
Chiara Lupi ${ }^{{ }^{*}+}$, Chiara Pracucci ${ }^{2+}$, Francesco De Cesaris ${ }^{1}$, Eleonora Rossi ${ }^{1}$, Pierangelo Geppetti ${ }^{1}$, Silvia Benemei ${ }^{1}$, \\ Valentina Galli' ${ }^{2}$, Brunella Occupati ${ }^{2}$, Viola Mazzucco², Guido Mannaioni ${ }^{2}$
}

From Abstracts from the 1st Joint ANIRCEF-SISC Congress

Rome, Italy. 29-31 October 2015

\section{Objective}

To evaluate the effectiveness, safety, and tolerability of a 12-month treatment with low doses of methadone (MT) (mean MT dosage $12.3 \mathrm{mg} \pm \mathrm{SD} 7.3$ ) as prophylaxis in patients affected by daily refractory headache and medication-overuse headache.

\section{Methods}

Prospective cohort study.

\section{Results}

Since May $3^{\text {rd }}, 2012$ up to January $8^{\text {th }}, 2015$, we enrolled 24 patients ( 18 females, 6 males; average age, 48 years) who were considered eligible to be treated with methadone. Nine patients dropped out because of adverse drug reactions $(n=4$, mean time of drop-out 7 days) or treatment ineffectiveness $(n=5$, mean time of drop-out 6 months). Six patients completed the 12-month treatment. After 1-year follow-up they still reported daily headache, however, they showed an impressive decrease of analgesic and/or antimigraine drug consumption (from 147.7 medications per month \pm SD 124 to 8.5 medications per month \pm SD 6.1) and a significant decrease of visual analogic scale (VAS) pain intensity (from $5.8 \pm$ SD 2.6 to $2.8 \pm$ SD 2.1). These patients were treated with daily methadone doses ranging from $5 \mathrm{mg}$ to $60 \mathrm{mg}$; methadone dosages were safe and well tolerated.

\section{Conclusions}

In patients affected by daily refractory headache and medication-overuse headache, who are exposed to the risk of serious side effects due to prolonged analgesic and/or antimigraine treatment, prophylaxis with low-dose methadone therapy seems to represent an effective therapeutic option.

Written informed consent to publication was obtained from the patient(s).

\section{Authors' details}

${ }^{1}$ Headache Centre, Careggi University Hospital, University of Florence, Florence, Italy. ${ }^{2}$ Toxicology Unit, Careggi University Hospital, Florence, Italy.

Published: 28 September 2015

\section{doi:10.1186/1129-2377-16-S1-A118}

Cite this article as: Lupi et al:: P057. Prophylaxis with low-dose methadone in patients affected by daily refractory headache and medication-overuse headache: a prospective cohort study (METACEF study). The Journal of Headache and Pain 2015 16(Suppl 1):A118.

\footnotetext{
* Correspondence: chiara.lupi@unifi.it

† Contributed equally

${ }^{1}$ Headache Centre, Careggi University Hospital, University of Florence,

Florence, Italy

Full list of author information is available at the end of the article
} creativecommons.org/licenses/by/4.0), which permits unrestricted use, distribution, and reproduction in any medium, provided the original work is properly cited. The Creative Commons Public Domain Dedication waiver (http://creativecommons.org/publicdomain/ zero/1.0/) applies to the data made available in this article, unless otherwise stated. 